\title{
Does substrate colour affect the visual appearance of gilded medieval sculptures? Part I: colorimetry and interferometric microscopy of gilded models
}

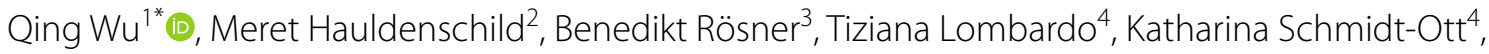 \\ Benjamin Watts ${ }^{3}$, Frithjof Nolting ${ }^{3}$ and David Ganz ${ }^{1}$
}

\begin{abstract}
In the history of medieval gilding, a common view has been circulated for centuries that the substrate colour can influence the visual appearance of a gilded surface. In order to fully understand the correlation between the gilding substrate and the colour appearance of the gold leaf laid above, in this paper (Part I) analytical techniques such as colorimetry and interferometric microscopy are implemented on models made from modern gold leaves. This study demonstrates that the substrate colour is not perceptible for gold leaf of at least $100 \mathrm{~nm}$ thickness, however the surface burnishing can greatly alter the visual appearance of a gold surface, and the quality of the burnishing is dependent on the substrate materials. Additionally, surface roughness and texture of the substrate can play supplementary roles, which can be visually observed through digital microscopy and quantified through interferometric microscopy. The findings in this paper will form the basis for the study of gold leaf samples taken from medieval European gilded sculptures in Part II.
\end{abstract}

Keywords: Medieval, Gilding, Surface, Colour, Substrate, Colorimetry, Interferometric microscopy

\section{Introduction}

As the climax epoch for altars and altar sculptures, the late Middle Ages exhibited exquisite art technologies and complex materials in the sculpting, carving and polychromy of these artefacts. Gilding, as the most important component of medieval polychromy, has been extensively used in sculptures and altarpieces, as well as other artworks such as panel paintings, wall paintings, illumination books and textiles, in order to show the wealth of a person, state or country and to exhibit the magnificence and splendour of the "House of God" and the divine nature of saints [1].

\footnotetext{
*Correspondence: qing.wu@uzh.ch

${ }^{1}$ University of Zurich, Raemistrasse 73, 8006 Zurich, Switzerland

Full list of author information is available at the end of the article
}

Although many medieval sculptures were destroyed in the following Reformation, some have survived and a few have even been well preserved. Based on these artefacts, art historians and researchers have brought forward interesting theories and arguments regarding the technologies of medieval gilding. One widely accepted point of view states that the colour of the gilding substrate plays a crucial role in the visual appearance or perception of medieval gilded artefacts due to the transparency of the gold leaf of that time [2]. This view sounds plausible and has sometimes been used to explain why certain substrate colours such as red, yellow and white have been frequently observed in medieval gilding. For example, some researchers argue that preparatory layers of fine yellow ochre can lend a warmer tone to mordant gilding [3]; a chromatic function of coloured bole is to give a warm red or ochre tonality to the gold surface [4]; a white
Springer Open

(c) The Author(s) 2020, corrected publication 2022. Open Access This article is licensed under a Creative Commons Attribution 4.0 International License, which permits use, sharing, adaptation, distribution and reproduction in any medium or format, as long as you give appropriate credit to the original author(s) and the source, provide a link to the Creative Commons licence, and indicate if changes were made. The images or other third party material in this article are included in the article's Creative Commons licence, unless indicated otherwise in a credit line to the material. If material is not included in the article's Creative Commons licence and your intended use is not permitted by statutory regulation or exceeds the permitted use, you will need to obtain permission directly from the copyright holder. To view a copy of this licence, visit http://creativecommons.org/licenses/by/4.0/. The Creative Commons Public Domain Dedication waiver (http://creativecommons.org/publicdomain/zero/1.0/) applies to the data made available in this article, unless otherwise stated in a credit line to the data. 
a Water gilding: burnishable

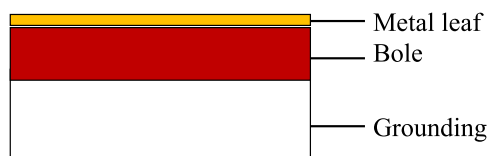

b Oil gilding: unburnishable

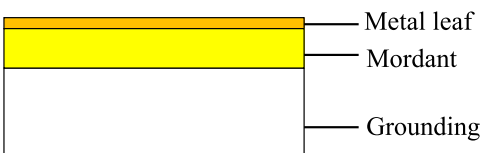

c Ground gilding: slightly burnishable

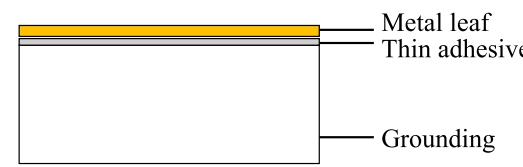

Fig. 1 Schematic illustrations of basic stratigraphy for a water gilding, $\mathbf{b}$ oil gilding and $\mathbf{c}$ ground gilding techniques

underlayer is supposed to enhance a cool, pale tonality of metal leaf such as silver [5]. In addition to modern literature, this point of view is also supported by historical documents such as medieval artists' treatises. For example, in The Craftsman's Handbook Cennini suggests using the red Armenian bole for water gilding [6].

Around this view a few researchers have recently demonstrated their understandings through building and analysing models. For example, Dumazet et al. use digital 3D models to simulate artefacts, in order to study correlations between gold leaf imperfections (e.g. holes), light reflection from substrate and optical transmission of gold leaf [7]. Mounier and Daniel have presented colorimetric observations of gold leaf on white, red and black substrates [8]. However, in these studies an important technological parameter of historical gold leaf, namely the actual leaf thickness, has not been linked or seriously investigated, leaving their arguments less supported. Furthermore, these studies mainly present the oil gilding (called Mixtion technique in these articles) on stone artefacts or wall paintings. Oil gilding is a common gilding technique, but the gold leaf laid above is unburnishable [9] and hence does not exhibit the typical metal gloss of a burnished gilded surface commonly observed on altars and altar sculptures that are mainly made from wood.

In order to fully understand the roles that the gilding substrate plays in the visual appearance of the gold surface of medieval sculptures, we have taken an integrated approach that combines investigations of models made from modern gold leaf (Part I) and samples of medieval gold leaf taken from artefacts (Part II). In the current paper, we focus on understanding the correlation between the appearance of the gold leaf and its substrate through colorimetry measurements on the models, which are made with traditional gilding techniques including water-, oil- and ground gilding on substrates with different materials (where appropriate for the gilding technique) and colours. The roughness of the gold surface is observed through digital microscopy and further quantified through interferometric microscopy. As supportive data, scanning electron microscopy coupled with energy dispersive $\mathrm{X}$-ray analysis (SEM-EDX) is also performed, in order to obtain the thickness and gold content of the modern gold leaves used for the models. This technique will however be discussed in detail in Part II, together with information regarding the technological features of medieval gold leaf samples.

\section{Background}

\section{Gilding techniques and stratigraphy}

Simply speaking, gilding is the process to attach metal leaves or foils onto a surface of other materials; water gilding (also called bole gilding) and oil gilding (or mordant gilding ${ }^{1}$ ) are the most common types of traditional gilding techniques. In water gilding, metal leaf is laid atop a "bole", which mainly contains clay and is usually bound with proteinaceous media; a high-gloss surface can be realized through a thorough surface burnishing $[9$, 10]. In oil gilding, siccative oil-based binding media are employed, and the metal leaf laid above is unburnishable and the surface hence appears relatively matte [10]. Due to the high metal gloss caused by the surface burnishing, water gilding is also called "glossy gilding" [9]. Before the water and oil gilding techniques became popular in European works of art, a variant of water gilding called ground gilding was the main gilding type prior to the mid thirteenth century $[2,5]$. In this technique, metal leaf is applied onto a polished ground by means of thin adhesives such as diluted animal glue or egg glair $[5,11]$, and can be slightly burnished [9].

Figure 1 presents schematic illustrations for the basic stratigraphy of these three types of gilding techniques, which contain (from bottom to top) grounding, bole (or mordant; or thin adhesive) and metal leaf. The main ingredients of the grounding are either chalk or gypsum, dependant on the geographical regions (generally chalk grounding for Northern Alps and gypsum for the South) [9]. Both chalk and gypsum groundings typically appear white and are usually bound with proteinaceous media. Bole and mordant are two common types of gilding substrates and usually appear colourful. The most common bole colour is red or red brown, which can be realized by adding red pigments (e.g. iron-based red ochre) or based

\footnotetext{
${ }^{1}$ Mordant refers to additional material to which unburnished metal leaf is attached; in northern Europe mordants are usually composed of non-aqueous media e.g. oil and resin [5].
} 
on the bole's own colour, for example, the famously red Armenian bole [2]. Another common substrate colour is yellow, which is the essential colour for mordant and can be made through adding yellow pigments (e.g. ochre, lead-tin yellow) into the drying oil or mordant [12], and has been frequently observed in matte gold areas such as the hair of saint statues [13]. In addition to gold leaf, which was extensively applied on the outer surface of saints' gown and altar background, silver and part-gold leaves (also called Zwischgold, refers to a metal leaf containing an upper gold layer and a lower silver layer [14, 15]) were also frequently observed in medieval gilded artefacts.

\section{Influencing factors to the visual effects of gilded surfaces}

The visual perception of a glossy surface such as metal is composed of the colour appearance and shininess [16], which respectively correspond to the diffuse and specular light reflection $[17,18]$ and can be affected by a few factors, such as the illumination pattern, surface roughness, and presence of a superficial layer [16, 19]. In the case of a gold leaf surface, the influencing factors could be extended to:

- Illumination. This mainly refers to the type, orientation and intensity of the light source, which certainly show a close relationship with the exhibition arrangement of the artefacts;

- Viewing condition. Human eyes have diverse resolving powers and a human observer can change viewing conditions and angles to make an appearance judgement [18].

- Surface coating. A surface coating layer (e.g. varnish) can change the surface roughness, and thus manipulate the light reflected from the surface. A protective varnish is usually not needed for a gold surface due to the chemical inertness of gold. However, a thin glue coating was sometimes partly applied onto a burnished gold surface, in order to create a matte/glossy aesthetic comparison [9].

- Surface burnishing. It is obvious to observe that a burnished gilded surface exhibits a high metal gloss while an unburnished surface appears relatively matte.

- Leaf imperfection. A careless surface burnishing can cause cracks or holes in the gold leaf. In certain magnitudes of such leaf imperfections, reflected light from the substrate could go through to reach the surface [7]. Similar effect would also occur if small areas of the substrate are exposed between adjacent gold leaves.

- Materials composition of gold leaf. The alloying elements play an essential role in the colour of a gold leaf. For example, Dumazet et al. [7] states that a gold alloy becomes greenish with the addition of $25 \%$ silver; while a copper content of $25 \%$ makes the alloy appear red.

- Leaf thickness. The thickness of a gold leaf is a critical parameter in how opaque it is and thus determines whether the substrate colour has the possibility to influences the visual appearance of the gold surface.

- Optical properties of gold. Gold is well known to strongly reflect and absorb visible light [20] and so only a very thin layer of gold would allow the transmission of light to illuminate the substrate or to allow light from the substrate to return to an observer.

Four of these factors, namely the illumination, viewing condition, surface coating and leaf imperfection, are strongly dependant on the individual objects or viewers, and hence are difficult to study in general. However, the materials composition of medieval gold leaf and its leaf thickness are either traceable in historical documents or can be analysed through scientific approaches, which will be discussed in detail in Part II.

The thickness of the gold leaf is a critical factor in whether the substrate colour is able to influence the appearance of the gilded surface. For the hypothesis to be true, light from an external source would need to be transmitted through the gold surface (i.e. not reflected) and the leaf thickness (i.e. not absorbed), then be reflected from the substrate to impart its colour and be transmitted through the leaf again to reach an observer. According to Loebich [20], if a pure gold leaf is $50 \mathrm{~nm}$ thick, then only about $10 \%$ of the incident light $(\lambda=492 \mathrm{~nm}$; cyan) can transmit through this gold leaf, which would be reduced to $10 \%$ on the return passage for about $1 \%(10 \% \times 10 \%)$ of the original light leaving the surface to be observable. This is without factoring in further losses due to reflectivity when entering the gold surface or when reflecting from the substrate. A gold film that is about $100 \mathrm{~nm}$ thick (similar to the modern gold leaves used in this study) cannot be expected to show any significant light transparency. A reproduced graph regarding the reflectivity and light transmission of thin gold films in terms of their thicknesses is presented in Additional file 1: Fig. S1. Colour measurements on the self-made models are therefore expected to show that the substrate colour does not affect the appearance of a gilded surface, but that variations in appearance may be caused by other factors. Surface burnishing is an important part of water gilding and well known to strongly affect the appearance of the gilded surface; and it is thus of great significance 


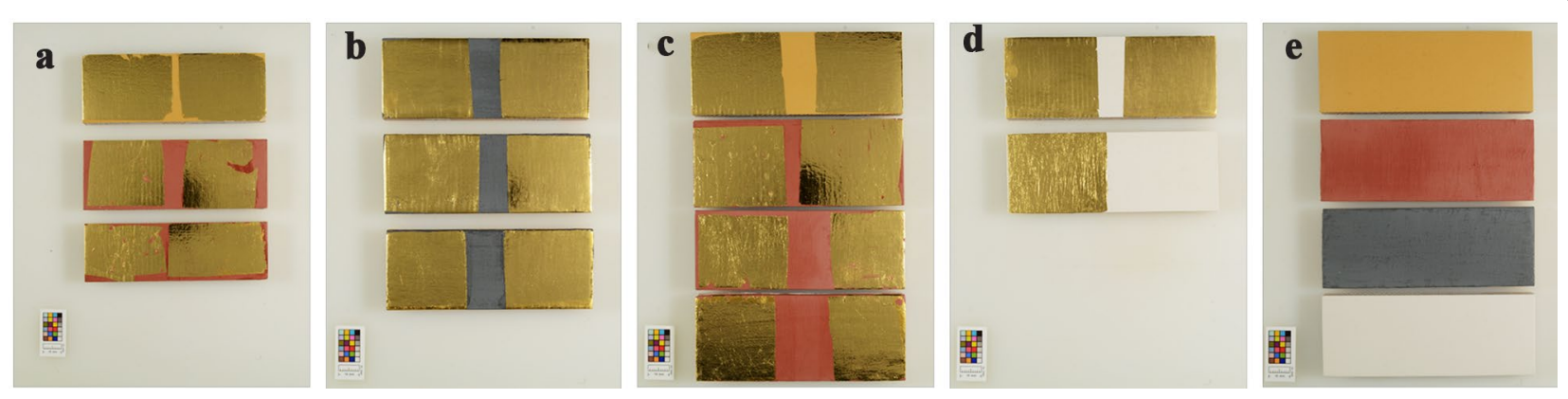

Fig. 2 a Poliergold models with yellow and red bole substrates including (from top to bottom) "y4_pg","r1_pg" and "r5_pgx2"; b Doppelgold models with blue-grey bole substrates including "b1_dg", "b4_dg" and "b2_dgx2"; c Doppelgold models with yellow and red bole substrates including "y7_ dg", "r7_dg", "r9_dg" and "r10_dgx2"; d Doppelgold models including the ground gilding model "w1_dg" and the oil gilding model "w4_dg_oil"; in the latter a gold size layer is located between the white ground and gold leaf, and thus invisible in the image; e bare substrates including yellow bole, red bole, blue-grey bole and white ground. The dark areas in the gilded sections of some models are the reflection of the camera lens

for historical gilded artefacts. The effect of burnishing is therefore a focus of this paper.

\section{Methods}

Gilding techniques, materials and nomenclature of models A total of twelve models (Fig. 2) were produced in March 2019 (3) and March 2020 (9) with traditional gilding techniques, including one ground gilding, one oil gilding and ten water gilding models.

In the models made in 2019, Spezial-Poliergold-AltgoldDunkel (from Deffner E Johann, Germany) was applied only with the water gilding technique. In the models made in 2020, ground gilding and oil gilding techniques were also added into the model production; and due to a shortage of Poliergold, Dukaten-Doppelgold (from Noris Blattgold, Germany) was used. Although manufacturers claim a gold purity of 22.5 carat for Poliergold ${ }^{2}$ and 23 carat for Doppelgold [21], SEM-EDX quantification on samples shows that these two types of gold leaf actually have very close gold contents (23.1-23.2 carat), with an Au:Ag:Cu mass ratio of 96.8:2.1:1.1 for Poliergold and 96.6:1.8:1.6 for Doppelgold; and their average leaf thickness is $96 \pm 9$ and $116 \pm 16 \mathrm{~nm}$ respectively. Details of the SEM-EDX measurements are presented in Part II.

A chalk ground bound with diluted animal glue was used as the grounding for all models. Three types of gilding substrates including the coloured (red, yellow, bluegrey) bole, oil-based gold size (Mixtion à dorer from Lefranc $\mathcal{E}$ Bourgeois, France) (half-transparent, light brown) and white chalk ground were respectively used to apply gold leaf with the water, oil and ground gilding techniques. The applied gold leaf was then either burnished ("b") or kept unburnished ("nb"). Here, it is

\footnotetext{
${ }^{2}$ Gold purity statement in the gold leaf packaging, which is included in the gilder's kit purchased from Deffner \& Johan, Germany.
}

worthwhile to point out that surface burnishing was performed manually with an agate burnishing tool in one direction of the surface plane in order to produce a high metal gloss; variations in effect are therefore dependent on a few factors such as applied pressure, rubbing speed and substrate moistness/softness, which are not easy to precisely control in a manual process. Technological details regarding the models are presented in Table 1 and more details of production procedures are presented in Additional file 1: Section 3.

Note that no adhesive was needed for water gilding models. Instead, a mixture of ethanol and water (1:2 by volume), functioned as the wetting agent and was brushed onto the bole immediately before the application of gold leaf. A diluted water-based rabbit skin glue $(1.5 \%$ by weight) was applied onto the white ground substrate of the ground gilding model; it was also used as adhesive between the gold leaves in the additional models with two layers of gold leaf, while the first layer of gold leaf in such models was still applied onto the bole with the ethanol/water mixture. In the oil gilding model, the gold size layer was used as both substrate and adhesive. The gold leaf was applied above the gold size when it was almost dry but still tacky.

The model names form a shorthand code describing their construction. They are composed of the substrate colour and identification number, followed by an underscore and the gold leaf type, as shown in Table 1. For example, "y4_pg" refers to "No. 4 yellow bole substrate applied with Poliergold", while "w1_dg" means "No. 1 white ground substrate applied with Doppelgold". Here "y" refers "yellow", "r" for "red", "b" for "blue-grey", "w" for "white", "pg" for "Poliergold" and "dg" for "Doppelgold". Note that double layers of gold leaf were applied on some additional water gilding models, indicated with a " $x 2$ " suffix. In the oil gilding model, the gold size layer is fully 


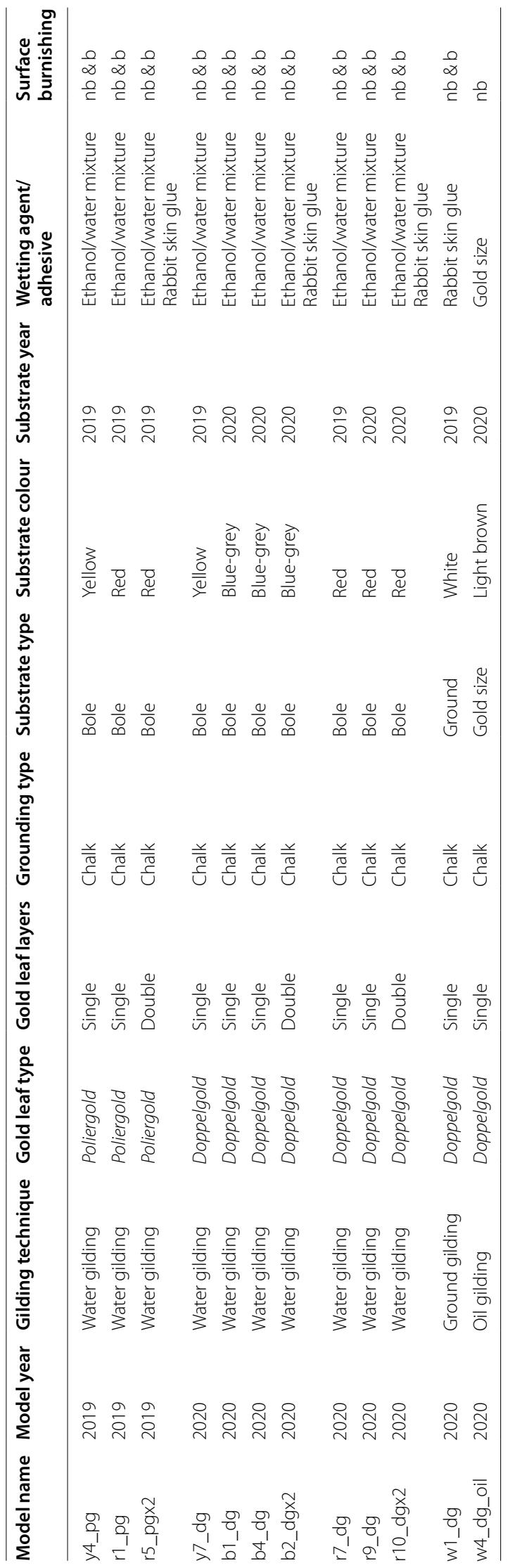


covered by the gold leaf and invisible to the observers, and thus the white ground colour "w" is still used in its name. In order to differentiate the ground and oil gilding models, the latter's name is suffixed with "_oil”.

Further, in the water gilding and ground gilding models, the gold surface on the left half was unburnished and that on the right half was burnished. Therefore, each such model is divided into two sub-models, labelled with "nb" (non-burnished) and "b" (burnished). For example, "y4_pg_nb" refers to "No. 4 yellow bole substrate applied with non-burnished Poliergold". The oil gilding model is unburnishable and therefore there is only one sub-model, labelled as “_oil_nb”.

\section{Analysis techniques and experimental conditions}

Colour measurements on models were implemented through a portable spectrophotometer Konica Minolta CM-2600d. Two measurement modes 'Specular Component Included' (SCI) and 'Specular Component Excluded' (SCE) were used for each measurement, with both 'Medium Area View' (MAV, $\varnothing 8 \mathrm{~mm}$ ) and 'Small Area View' (SAV, Ø $3 \mathrm{~mm}$ ) apertures. A built-in colour system CIE $L * a * b *$ with a standard illuminant D65 was applied for the colour analysis of a surface, through which three colorimetric values are obtained, including $L^{*}$ for the lightness from black (0) to white (100), $\mathrm{a}^{*}$ from green (-) to red $(+)$, and $b^{*}$ from blue $(-)$ to yellow $(+)[22]$. A colour difference $\left(\Delta E^{*} \mathrm{ab}\right)$ between a sample and the target spot is calculated based on the difference of colorimetric values, i.e. $\Delta \mathrm{L}^{*}$ ("+" lighter, "-" darker), $\Delta \mathrm{a}^{*}$ ("+" redder, "-" greener) and $\Delta b^{*}$ ("+" yellower, "-" bluer) [23]. A commonly accepted Just Noticeable Difference (JND) value of $\Delta E^{*}$ ab is $2.3[22,24]$. Calculation formula for a colour difference is presented in "Appendix".

A digital microscope Keyence VHX-5000 was used for observations on the roughness and texture of the model surfaces at the Paul Scherrer Institute (PSI), with the $200 \times$ objective, MIX lighting and HDR image quality. Positions representing general surface conditions for the non-burnished, burnished gold surfaces and bare substrate areas of the models were selected for imaging through a $3 \mathrm{D}$-Stitching mode, in which $3 \times 3$ images were stitched into a total area of $3798 \times 2954 \mu \mathrm{m}$. The entire region is displayed in focus by measuring a focal stack with a vertical pitch of $20 \mathrm{um}$.

A Zygo NiewView 5010 white light interferometer was used for surface roughness measurements at the PSI. The $2.5 \times$ objective used in the study provides a total magnification of 100, a numerical aperture of 0.075 , and a field of view of $1.4 \times 1.0 \mathrm{~mm}$. The samples were placed and aligned under the microscope, and subsequently scanned in height. With typical peak-to-valley values of $2-10 \mu \mathrm{m}$, a scanning range of $40 \mu \mathrm{m}$ was used.
As supportive data, SEM-EDX was implemented for the gold content and leaf thickness of the gold leaves used for the models. The experimental conditions of SEM are presented in Additional file 1: Section 2.

\section{Results and discussion \\ Colour measurements Measurements on substrates}

In order to ensure the reliability of the colour measurements on the gold surface of the models, it is necessary to first check the colour quality of the substrates. Four substrate groups including yellow, red, blue-grey boles and white grounds, which were made either in 2019 or in 2020 (details presented in Table 1), were investigated through colorimetry with the MAV aperture. Note that the oil-based gold size was not measured, due to its tacky nature and tendency to easily collect dust. Measurement results show that there is no significant colour difference (for both SCE and SCI values of $\Delta \mathrm{E}^{*} \mathrm{ab}$ ) within the individual substrates and within the same substrate groups, indicating that the colours of the substrates are even and homogeneous. Colorimetric data of the substrates is presented in Additional file 1: Table S1.

\section{Measurements on gold surfaces with different apertures}

During the colour measurements on gold surface of models, it is observed that the SCI values of $\Delta \mathrm{E}^{*} \mathrm{ab}$ for almost all "nb" and "b" sub-models are below JND, which is inconsistent with our visual perception that the burnished gold surface appears darker and more saturated than the unburnished one. Indeed, according to the colorimeter manufacturer Konica Minolta, the SCE mode (i.e. diffuse reflection ${ }^{3}$ ) is similar to the visual perceptions by human eyes for a glossy surface [25]. Therefore, further analysis is only focused on the SCE data.

Both MAV and SAV apertures were used for the colour measurements on gold surface. For MAV measurements, about 20 sample spots were selected on each "nb" and " $b$ " sub-models. Minor imperfections in the gold leaf (e.g. fine scratches, small worn spots and stains), which are usually generated during the application and burnishing procedures, were included in these spots. In SAV measurements about 25 spots were selected, in which the minor defects were avoided. An example of the selection of MAV and SAV measurement spots on Model "y4_pg" is presented in Additional file 1: Fig. S3. The comparison between the MAV and SAV measurement data is expected to show whether minor leaf defects could affect

\footnotetext{
3 The total light reflection from a surface includes a specular reflection and diffuse reflection. In the SCE mode of colorimetry, the specular component is excluded and therefore only the diffuse reflection is recorded and analysed [17].
} 

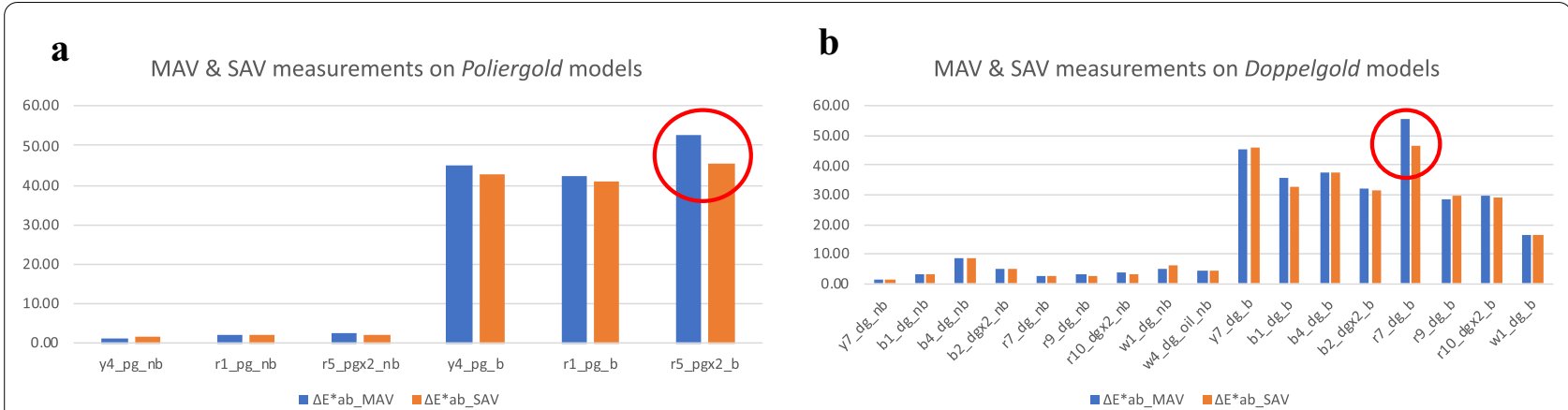

Fig. 3 Comparison between MAV (blue columns) and SAV (orange columns) measurements on a Poliergold models and b Doppelgold models. Corresponding data is available in Additional file 1:Table S2

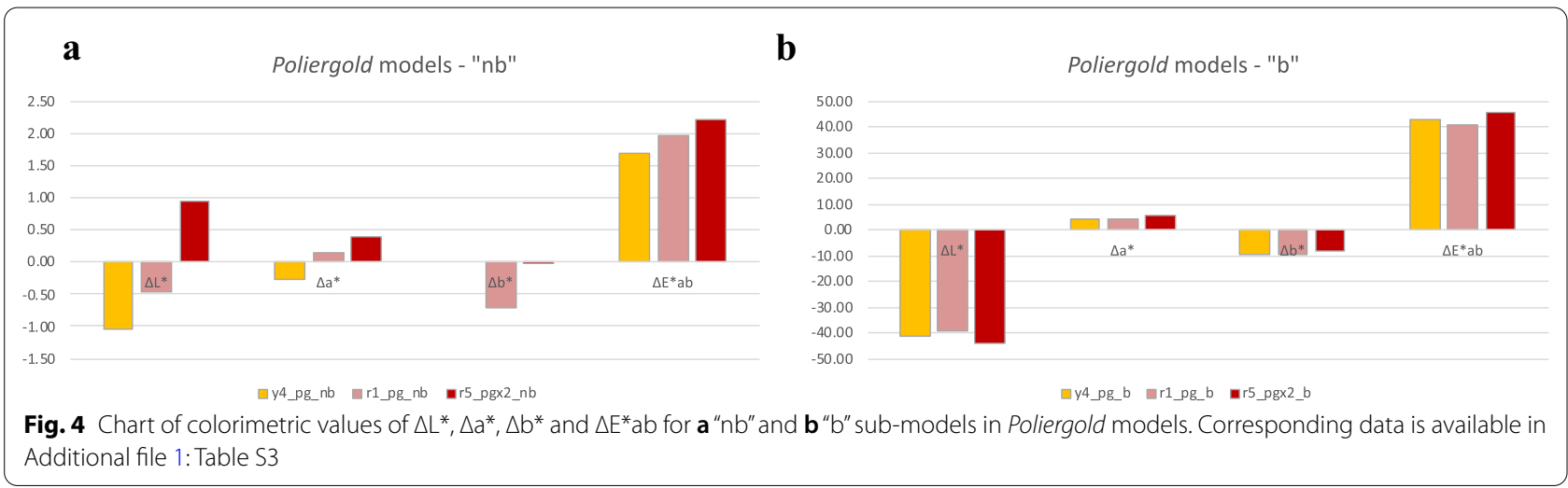

the visual appearance of the gold surface. Note that during the analysis of SAV data around 1-3 spots in a few sub-models, which show unusual $\Delta \mathrm{E}^{*}$ ab values compared to the averaged one, were further excluded.

Figure 3 presents the data charts of the MAV and SAV colour differences $\left(\triangle \mathrm{E}^{*} \mathrm{ab}\right)$ measured in Poliergold models (a) and Doppelgold models (b). It is obvious that almost all sub-models have very close $\Delta \mathrm{E}^{*} \mathrm{ab}$ values, except for "r5_pgx2_b" and "r7_dg_b", which show higher values in MAV measurements than SAV by ca. 7 and 9 units respectively. We are not certain about the reason for such colour discrepancy. It is assumed that the MAV measurement spots in these two sub-models might contain relatively large defects, which could lead to certain levels of colour change of the gold surface. The comparison between the MAV and SAV data indicates that minor imperfections in the gold leaf do not significantly influence the colour appearance of the gold surface. Further analysis is focused on the SAV data.

\section{Measurements on Poliergold models}

The Poliergold models include three water gilding models "y4_pg", "r1_pg" and "r5_pgx2". Figure 4 shows that the colour differences (compared to the target) of the three "nb" sub-models are not significant $\left(\Delta \mathrm{E}^{*}\right.$ ab values $\left.<\mathrm{JND}\right)$; the same also applies for their " $b$ " sub-models. In the latter, the $\Delta \mathrm{L}^{*}$ values drop dramatically (by $39-43$ units compared to the corresponding "nb" sub-models), followed by the $\Delta \mathrm{b}^{*}$ values (drop by $8-9$ units); while the $\Delta \mathrm{a}^{*}$ values slightly increase (by ca. $4-5$ units). This observation indicates that after surface burnishing the gold leaf appears much darker and its colour change is in the direction of blue and red. Compared to "y4_pg_b" and "r1_pg_b", the sub-model "r5_dgx2_b" seems even darker and more red-blueish (indicated with lower $\Delta \mathrm{L}^{*}$ and $\Delta \mathrm{b}$, and higher $\Delta \mathrm{a}^{*}$ ). We believe that this effect was likely caused by a stronger surface burnishing.

Since the gold leaves on differently coloured (i.e. red and yellow) bole substrates do not show significant colour change in both unburnished and burnished states, we have evidence against the hypothesis that the substrate colour plays a role in the colour appearance of the gold leaf laid above. However, to be conclusive it is necessary to study more models, in order to better understand the correlation between the colour of the gold surface and its substrate. 
a

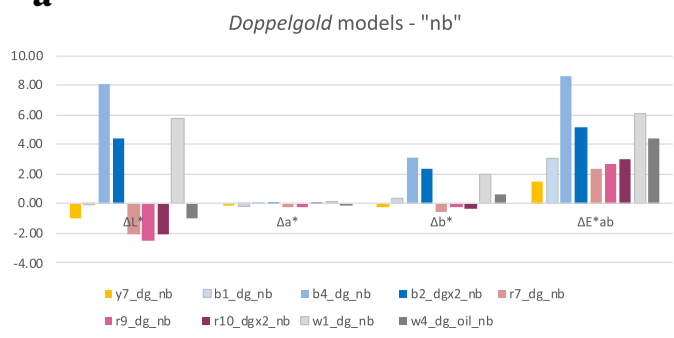

c

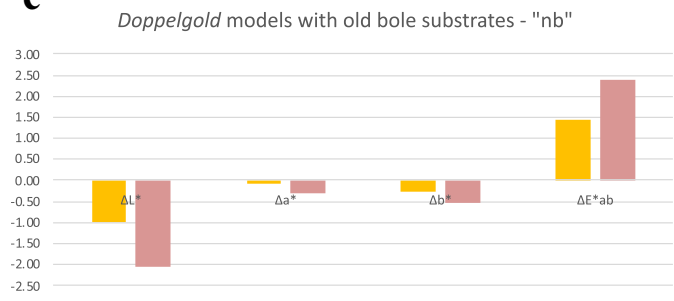

$\varpi y 7 \_d g \_n b \quad \varpi r 7 \_d g \_n b$

e

Doppelgold models with new bole substrates - "nb"

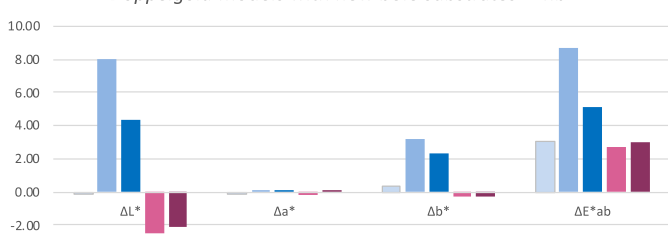

$-4.00$

\section{g}

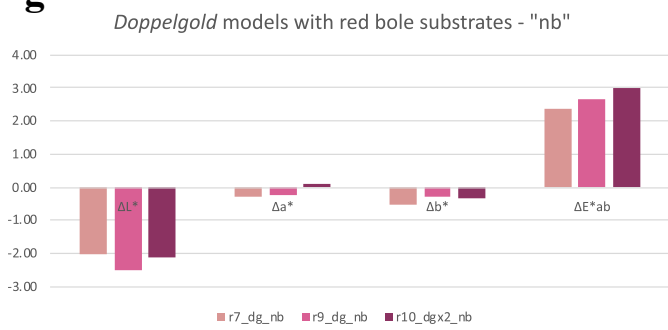

i

Doppelgold models with different gilding techniques - "nb"

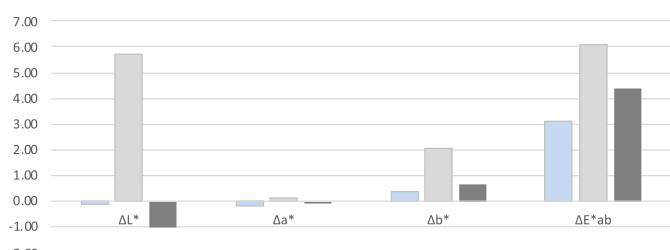

-b1_dg_nb घw1_dg_nb $-w_{4}$ _dg_oil_nb b

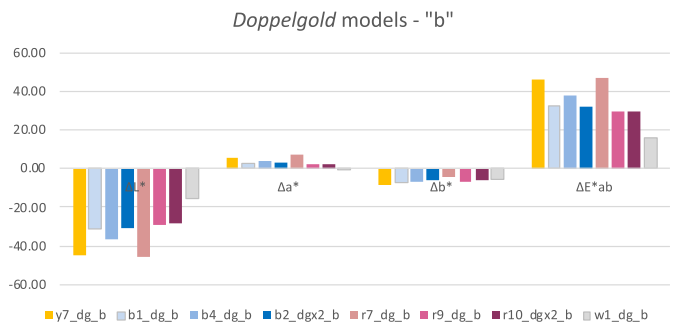

d

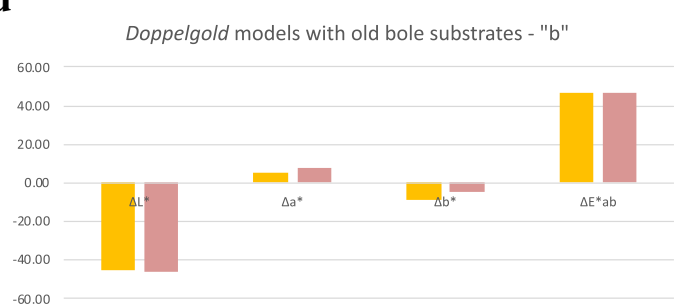

f

$=y 7_{-} \mathrm{dg} \_\mathrm{b}=r \mathrm{r}_{-} \mathrm{dg}$

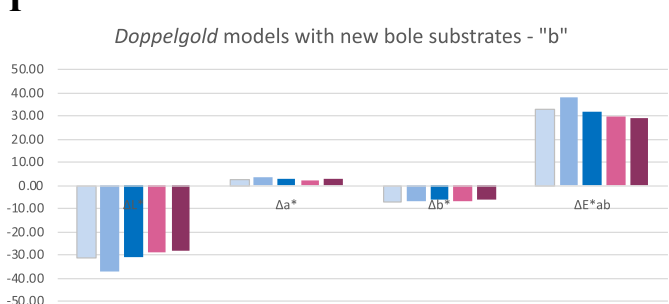

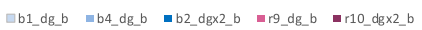

h

Doppelgold models with red bole substrates - "b"

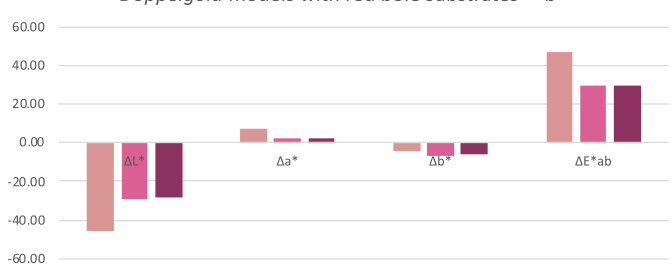

j

Doppelgold models with different gilding techniques - "b"

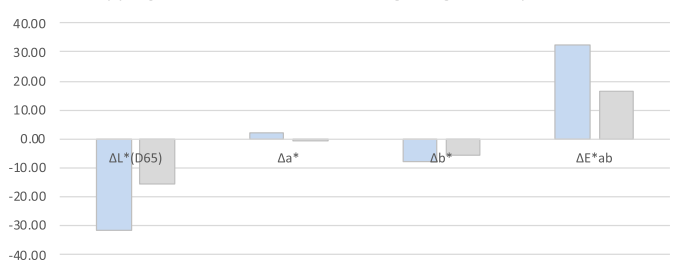

$\square \mathrm{b} 1 \mathrm{~d} \mathrm{dg} \_\mathrm{b} \square \mathrm{w} \mathrm{w}_{-} \mathrm{dg} \_\mathrm{b}$

Fig. 5 Chart of colorimetric values of $\Delta L^{*}, \Delta a^{*}, \Delta b^{*}$ and $\Delta E^{*} a b$ for $\mathbf{a}$ " $n b^{\prime \prime}$ and $\mathbf{b}$ "b" sub-models in all Doppelgold models; $\mathbf{c}$ " $n b^{\prime}$ " and $\mathbf{d}$ "b" sub-models with old bole substrates; $\mathbf{e}$ "nb" and $\mathbf{f}$ "b" sub-models with new bole substrates; $\mathbf{g}$ "nb" and $\mathbf{j}$ "b" sub-models with red bole substrates; $\mathbf{i}$ "nb" and $\mathbf{j}$ "b" sub-models made with different gilding techniques. Corresponding data is available in Additional file 1: Table S4

\section{Measurements on Doppelgold models}

Figure $5 \mathrm{a}$, b presents the colour measurements of nine Doppelgold models, including one ground gilding, one oil gilding and seven water gilding models. Four subsets of models with specific features (Fig. $5 \mathrm{c}-\mathrm{j}$ ) were further compared and analysed.

- Subset 1: Models with old bole substrates 
The first colour comparison was implemented between "y7_dg" and "r7_dg" (Fig. 5c, d), in which the bole substrates " $y 7$ " and "r7" were made in 2019. It is obvious that the colorimetric data for both "nb" and " $b$ " sub-models of these two models are very similar, indicating that there is no significant colour difference between the gold surfaces on the differently coloured bole substrates. Such observation further confirms the measurement output from the Poliergold models.

- Subset 2: Models with new bole substrates

Five models ("b1_dg", "b4_dg", "b2_dgx2", "r9_dg" and "r10_dgx2") were built on new bole substrates made in 2020 (Fig. 5e, f). Sub-models "b4_dg_nb" and "b2 dgx2_nb" show higher $L^{*}$ values (76.43 and 72.74) than that of "b1_dg_nb" (68.28), indicating relatively higher diffuse light reflection and also leading to their slightly different $\Delta \mathrm{E}^{*} \mathrm{ab}$ values $(8.66,5.16$ and 2.67$)$. Indeed, digital microscopy images of these three "nb" sub-models (Fig. 7a-c) show that the latter two submodels appear rougher than the former. Here, it is worth noting that the blue-grey bole materials seem to contain larger pigment or filler particles than the yellow and red bole materials; and the substrate "b1" was slightly sanded to obtain a relatively smoother surface than "b2" and "b4", for the purpose of comparison. Since "b1", "b2" and "b4" exhibit different levels of surface roughness but very similar colorimetric values (Additional file 1: Table S1), the colour discrepancy in their "nb" sub-models indicates that the surface roughness of the substrate could play a role in the visual appearance of an unburnished gold leaf laid above.

- Models "r9_dg" and "r10_dgx2" show almost the same colorimetric values in both their "nb" and " $b$ " sub-models, indicating that there is no significant colour difference between the single- and double-layered gold leaf. This is also an evidence to prove that the slight colour difference between the Poliergold models "r1_pg_b" and "r5_pgx2_b" was likely caused by different magnitudes of surface burnishing.

It is interesting to observe that the $\Delta \mathrm{E}^{*} \mathrm{ab}$ values of "r9_dg_nb" (2.67) and "r10_dgx2_nb" (3.00) are very close to that of "b1_dg_nb" (3.10), which could be attributed to the fact that the substrate "b1" was sanded to obtain a smoother surface and its roughness could be similar to the new red boles.

As for "b" sub-models, except for "b4_dg_b", the other four sub-models show close colorimetric values. The $\Delta \mathrm{E}^{*} \mathrm{ab}$ value of "b4_dg_b" is slightly higher than the others. Again, this could be attributed to a stronger surface burnishing.

- Subset 3: Models with red bole substrates
The "nb" sub-models of three models with red bole substrates ("r7_dg", "r9_dg" and "r10_dgx2) show very close colorimetric values; while "r7_dg_b" exhibits higher $\Delta \mathrm{E}^{*}$ ab values than the other two "b" submodels (Fig. 5g, h). Note that the substrates "r7", "r9" and " $\mathrm{r} 10$ " do not show significant differences in their colour measurements (Additional file 1: Table S1).

- Subset 4: Models made with different gilding techniques

This comparison is performed between the water gilding model "b1_dg", ground gilding model "w1_dg" and oil gilding model "w4_dg_oil" (Fig. 5i, j). Note that the comparison for "b" sub-models (j) is only performed between "b1_dg_b" and "w1_dg_b", since the gold surface in oil gilding is unburnishable. It is not surprising to observe that "w1_dg_b" shows much lower $\Delta \mathrm{E}^{*}$ ab value (16.23) compared to "b1_ dg_b" (32.62), which is mainly attributed to the fact that the L* value of "w1_dg_b" (53.10) is much higher than that of "b1_dg_b" (36.76) by ca. 16 units. This observation indicates that a poor-quality surface burnishing has been performed on this ground gilding model. Indeed, historical literature states that ground gilding can be only slightly burnished [9].

Fig. $5 \mathrm{i}$ show that the $\Delta \mathrm{E}^{*} \mathrm{ab}$ values of the three "nb" sub-models vary on a small scale, of which "w1_dg nb" shows the highest value of 6.08 , while the values of the other two are very close (3.10 for "b1_dg_nb"; 4.41 for "w4_dg_oil_nb"). This discrepancy also results from their different $L^{*}$ values: "w1_dg_nb" shows higher lightness (74.09) than the other two "nb" sub-models (68.28 and 67.36), indicating a slightly more diffuse light reflection. Since the chalk ground was polished by fine sandpaper and thus appears very flat and smooth, it is worth to further investigate why more light could be diffusely reflected from the gold leaf laid atop such a highly polished and flat substrate surface.

\section{Colour comparison between Poliergold models and Doppelgold models}

The analysis in the previous section exhibits some examples about the possible correlation between the surface roughness of the substrate and the colour change of the gold leaf. Therefore, the colour comparison between different gold leaves must be performed on the models with substrates of similar roughness, likely the substrates made at the same time.

The comparison was implemented between two Poliergold and two Doppelgold models with yellow and red bole substrates. Figure 6 show that these four models exhibit very close colorimetric values in both their "nb" and " $b$ " 

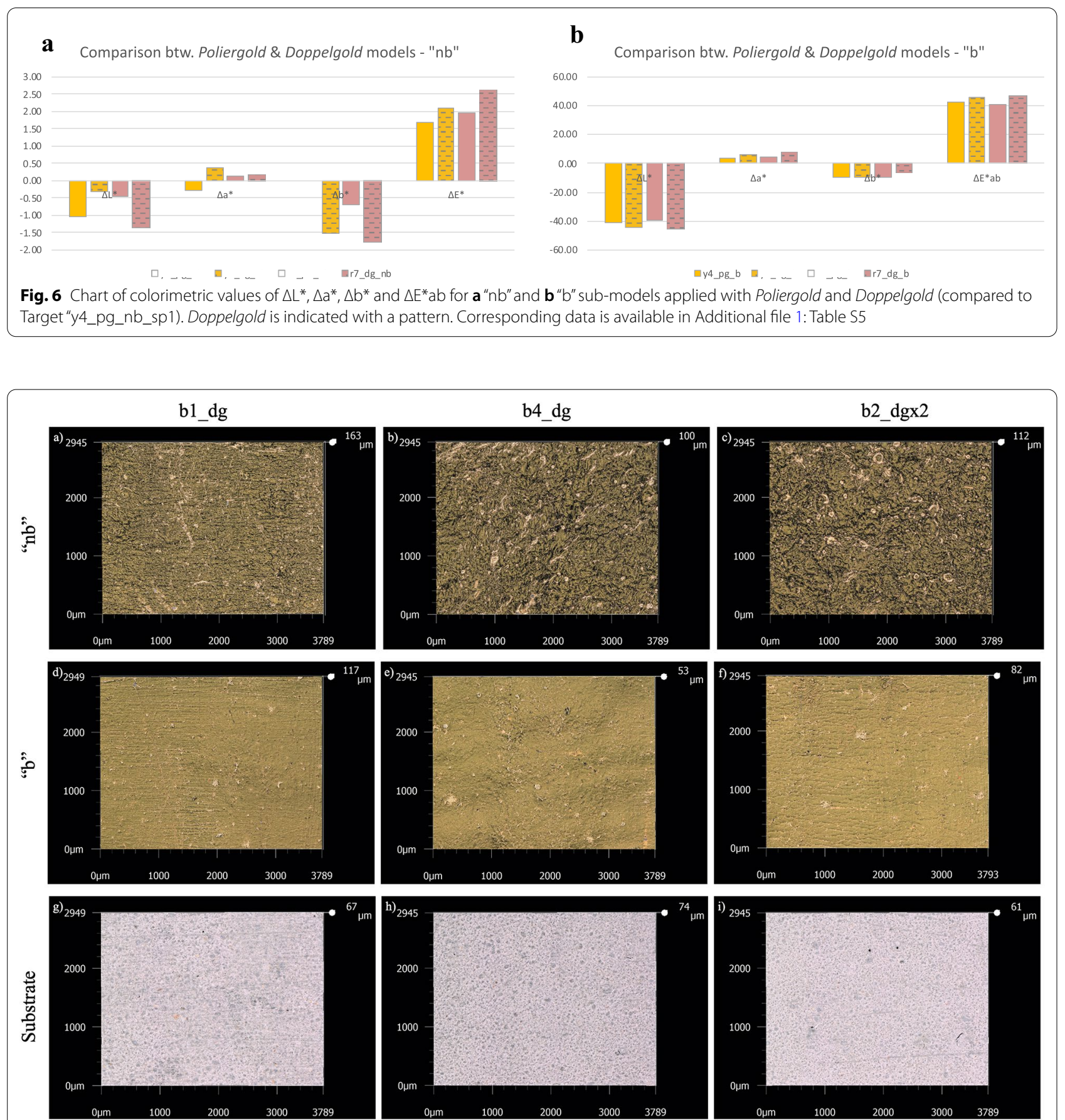

Fig. 7 Digital microscopy 3D-Stitching images for the "nb", "b" and substrate areas of the models with the blue-grey bole substrates "b1_dg", "b4_dg" and "b2_dgx2"

sub-models, indicating that the small discrepancies in the gold content and leaf thickness of the gold leaf do not cause significant colour change to its surface.

From the colour measurements on the models with different types of gilding techniques, gold leaves and substrates, we see strong evidence that the substrate colour does not play an essential role in the visual appearance of the gold leaf laid above. Instead, the surface burnishing can strongly alter the colour appearance of the gold leaf and its quality is dependent on the substrate materials. Within the three common gilding substrates, the coloured bole provides the best surface burnishing due 

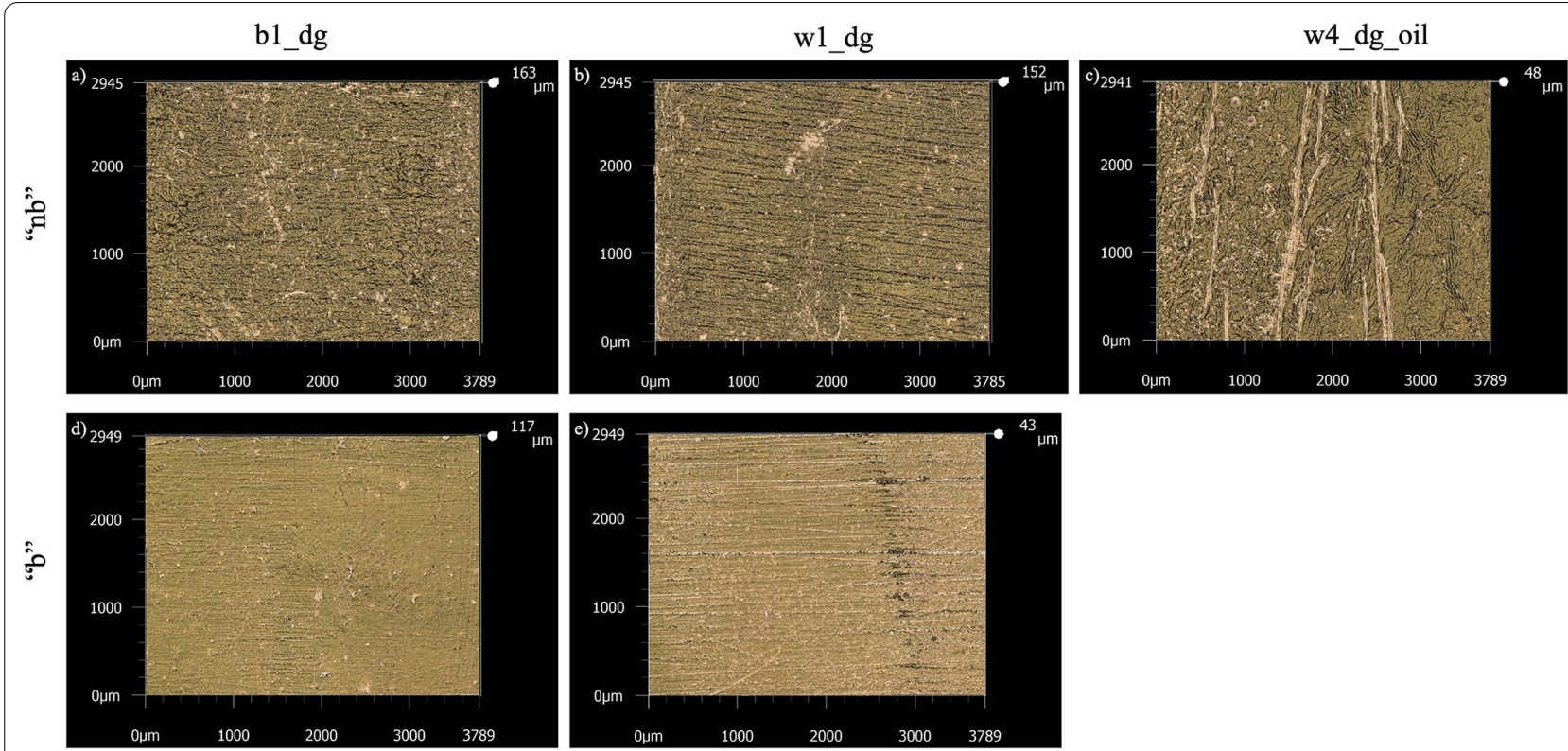

Fig. 8 Digital microscopy 3D-Stitching images for the "nb", "b" and substrate areas of the models made with different gilding techniques "b1_dg", "w1_dg" and "w4_dg_oil". Note that "w4_dg_oil" does not have a "b" sub-model

to the presence of its elastic clay ingredients, which correspondingly leads to more depth effects to the gold leaf laid above; while the gold surface above the ground substrate can be only slightly burnished due to the high hardness of the chalk ground. However, it is worth pointing out that the quality of surface burnishing is not only dependant on the substrate materials but also due to the implementers and preparation processing. Details are presented in Additional file 1: Section 3.1.

Surface roughness of the substrate seems to be another critical factor to influence the colour of the gold leaf. The correlation between the surface roughness of the substrate and the visual appearance of the gold leaf are further studied through digital microscopy and interferometric microscopy in the following sections.

\section{Digital microscopy imaging on models}

Figure 7 exhibits the digital microscopy (DM) images of three models with the blue-grey bole substrates ("b1_dg", "b4_dg", "b2_dgx2") through the 3D-stitching mode. Although it is known that the substrate "b1" was sanded to obtain a relatively smoother surface than "b2" and "b4", these three bare substrates cannot not be well differentiated in their DM images (Fig. $7 \mathrm{~g}-\mathrm{i}$ ). Instead, the substrate roughness can be reflected through the DM image of an unburnished gold leaf laid above, especially with the MIX lighting and the HDR image quality. The sub-model "b1_dg_nb" clearly exhibits a less rough gold surface than "b4_dg_nb" and "b2_dgx2_nb" (Fig. 7a-c); and it is not surprising to observe that after burnishing, all the " $\mathrm{b}$ " sub-models show smoother surfaces in a similar level (Fig. 7d-f) compared to their "nb" sub-models, indicating a greater specular/diffuse proportion ratio in the light reflection. The DM observations on these three models is consistent with their colorimetry measurements.

It is also interesting to compare the DM images of models with different gilding techniques. Figure 8 shows DM observations on the gold surfaces of "b1_dg", "w1_ dg" and "w4_dg_oil". These three models look similarly rough but with different textures in their " $\mathrm{nb}$ " and " $\mathrm{b}$ " sub-models respectively. For example, "b1_dg" exhibits a relatively even and homogenous texture (Fig. 8a, d); while "w1_dg" shows many fine horizontal lines in both its "nb" and "b" sub-models (Fig. 8b, e), although the surface burnishing was performed on the latter in the vertical direction. The fine horizontal lines present in "w1_dg" were likely caused by the sanding marks on its ground substrate, since the sanding and polishing of all chalk grounds were performed in this direction. Different from "w1_dg", the model "w4_dg_oil" shows a few larger-scaled vertical lines in its "nb" sub-model (Fig. 8c). Such vertical lines could be possibly attributed to the presence of leaf folds. Since the gold leaf in oil gilding is unburnishable, leaf folds created during the manual pressing with cotton balls cannot be flattened through a surface burnishing.

\section{Interferometric microscopy measurements on surface roughness of models}

The quantification of surface roughness was determined using interferometric microscopy. Measurement spots 

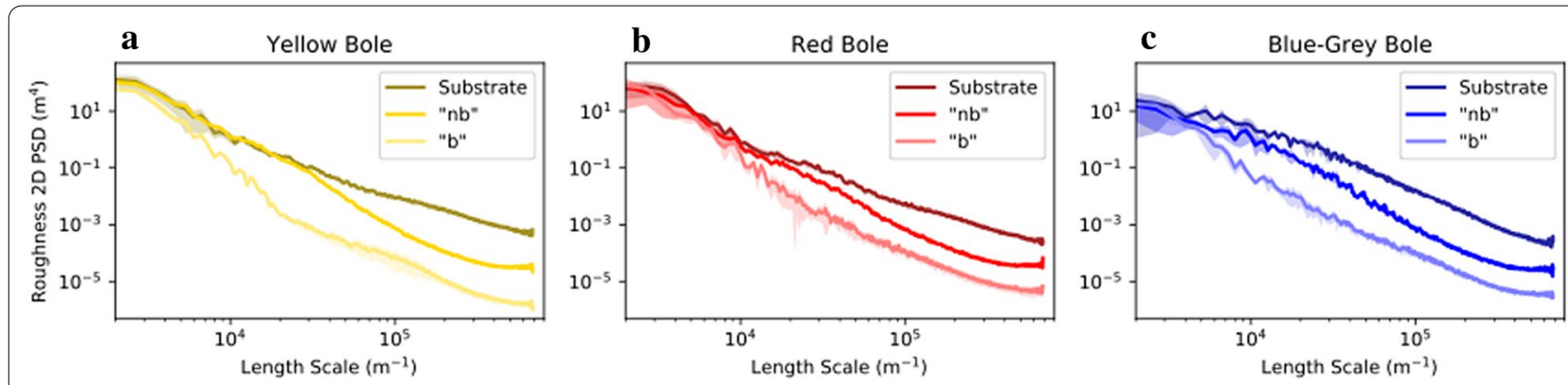

Fig. 9 Radially averaged 2D power spectral density (PSD) of surface topologies measured by interferometric microscopy for models with the yellow, red and blue-grey bole substrates. Lines show the average of multiple measurements, while shaded areas represent $90 \%$ confidence intervals

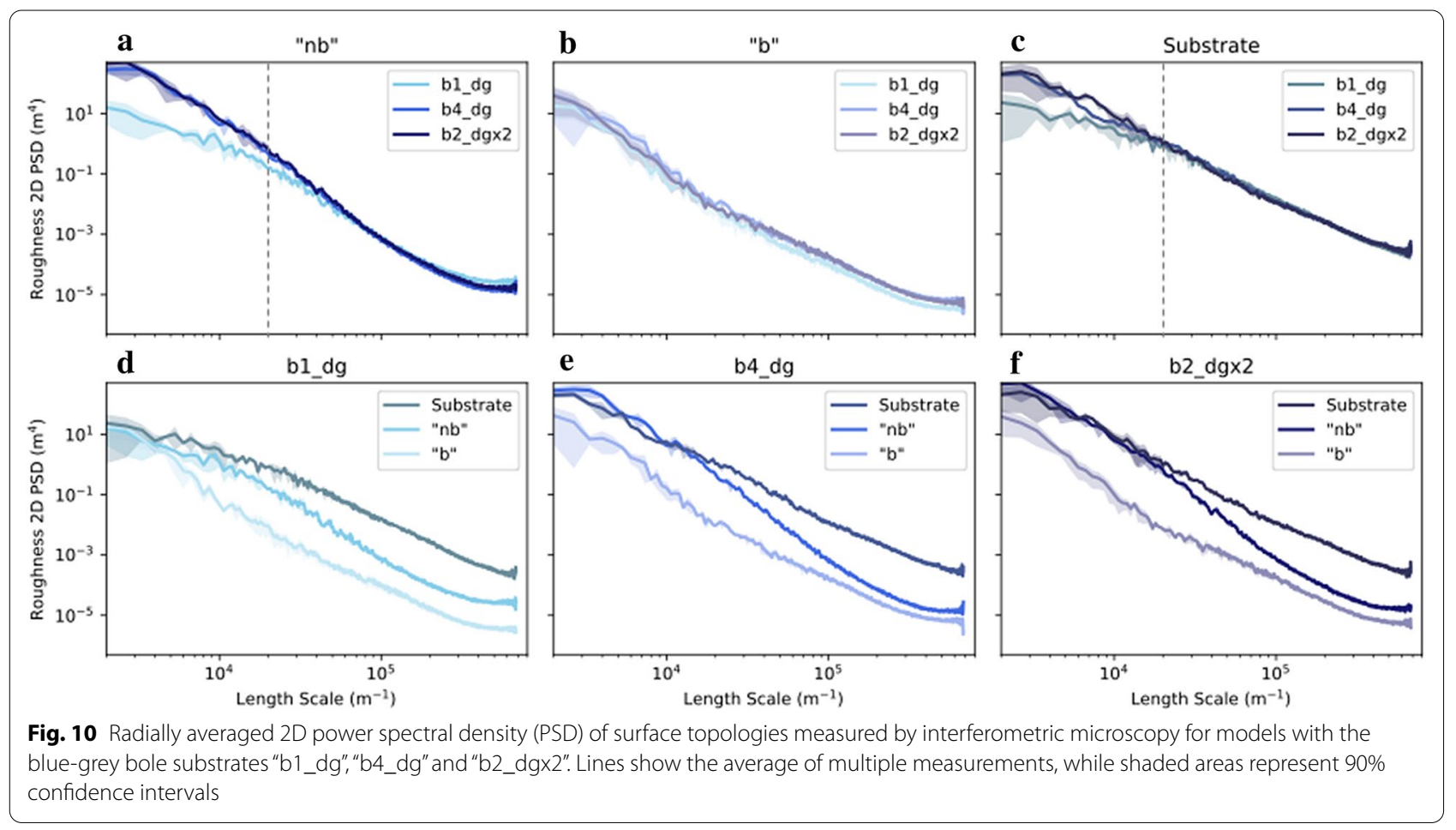

that represent general surface conditions were selected for each of the three areas in the models: "nb", "b" and bare substrate.

Figure 9 shows radially averaged 2D power spectral density (PSD) of the surface topologies of the three types of water gilding models investigated in this study as a quantitative measure of surface roughness [26], including models with yellow bole (a), red bole (b) and blue-grey bole substrates (c). A common trend of the roughness change between the bare substrate, unburnished ("nb") and burnished ("b") areas can be easily observed in each type of the models: the bare substrates show the highest roughness, while the "nb" sub-models show a similar roughness on the longer length scales (following the shape of the substrate) and a strong roughness decrease at short length scales, and the "b" sub-models show decreased roughness across all length scales.

The water gilding models with the blue-grey bole substrates ("b1_dg", "b4_dg" and "b2_dgx2") are further analysed in Fig. 10. Comparisons with respect to "nb", "b" and bare substrate are presented in Fig. 10a-c. The surface roughness of the "nb" sub-models in Fig. 10a shows that "b1_dg_nb" is significantly smoother than "b4_dg $\mathrm{nb}$ " and "b2_dgx2_nb" at the length scales larger than ca. $0.05 \mathrm{~mm}$; while below $0.05 \mathrm{~mm}$ the surfaces show very similar roughness. A similar situation is also observed 


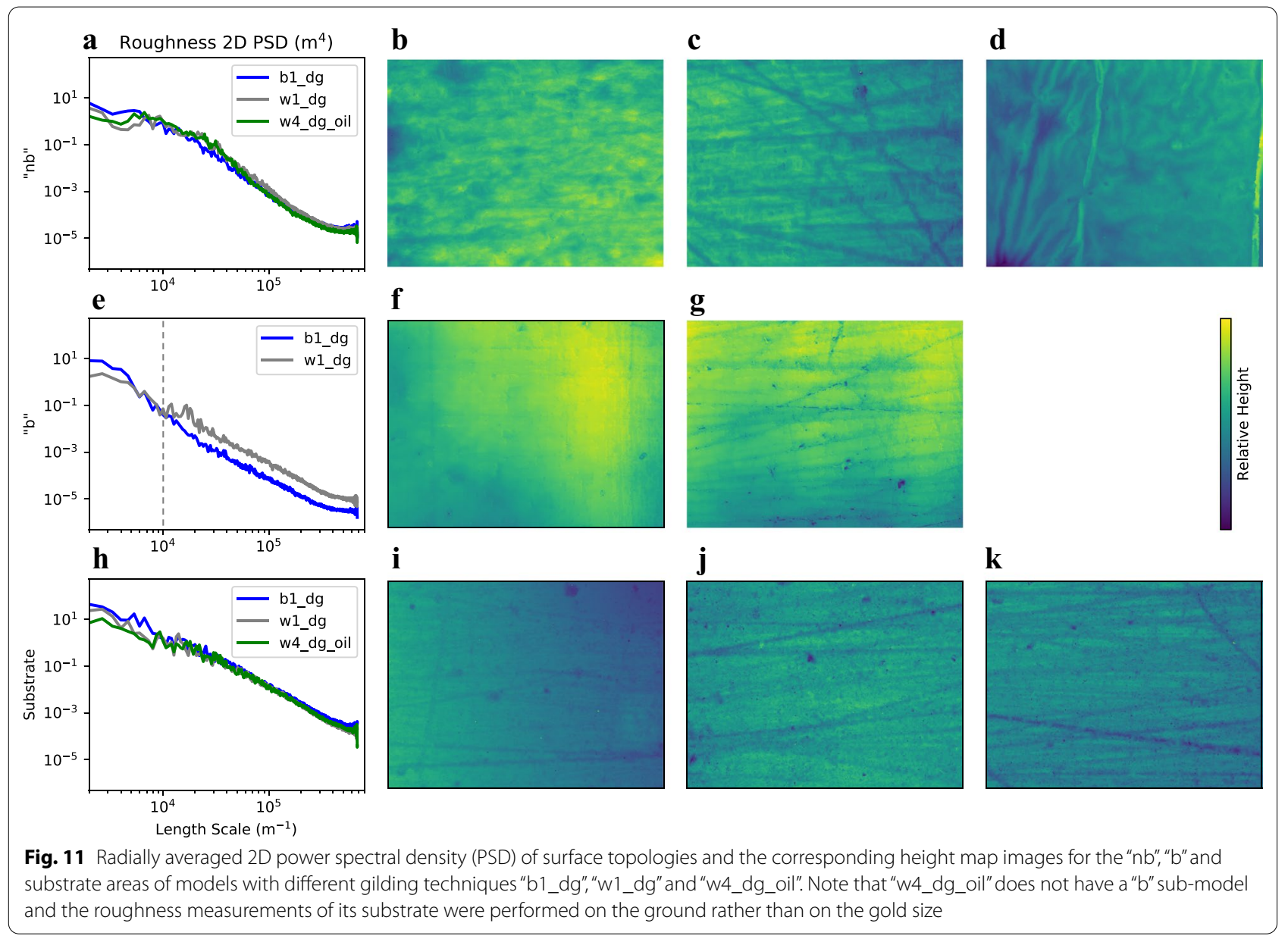

in their bare substrates in Fig. 10c where "b1" shows a lower roughness than "b4" and "b2" at the larger length scales, while in the smaller scales there is no difference. Comparing these to the "b" sub-models in Fig. 10b, we observe that burnishing causes a strong reduction in the surface roughness and now the three "b" sub-models show similar roughness in all length scales, indicating the performance of a good-quality surface burnishing on all these three models. The output of the roughness measurements is consistent with our observations through digital microscopy and colorimetry, providing strong evidence for a correlation between the surface roughness of the substrate and the colour appearance of the gold leaf. For example, the substrate "b1" was sanded to obtain a smoother surface (to a similar level as the yellow bole), and the gold leaf laid above ("b1_dg_nb") correspondingly shows the lowest roughness and smallest colour difference (compared to the target "y7_dg_nb_sp1") within this set of three models; after surface burnishing its surface roughness becomes similar to the other two models.

Figure 10d-f shows the comparison between "nb", "b" and substrate for individual models. It is clear that all "b" sub-models exhibit the lowest roughness, followed by the "nb" sub-models and the bare substrates are the roughest. The roughness change in this set of models is similar to the trends observed in Fig. 9.

Figure 11 presents the radially averaged 2D PSD roughness profiles and the corresponding interferometric microscopy images of three models produced with different gilding techniques (i.e. "b1_dg", "w1_dg" and "w4_dg_oil"), which were also observed through digital microscopy. Note that measurements of the substrate roughness of "w4_dg_oil" was performed on the chalk ground rather than the oil-based gold size due to the tacky nature of the latter. From the images shown in Fig. 11b-d, we can see that the three "nb" sub-models show different large-scale textures, however these differences are not reflected in the corresponding PSDs shown in Fig. 11a, due to a lack of statistics in the large length scale region. A similar situation is also observed in the roughness graphs of their bare substrates in Fig. 11h. However, the colour measurements show that the $\Delta E^{*} \mathrm{ab}$ values of "w1_dg_nb", "w4_dg_oil_nb" and "b1_dg_nb" are $6.08,4.41$ and 3.10 respectively; the relatively higher 
$\Delta E^{*}$ ab value of the former is mainly attributed to its higher $L^{*}$ value compared to those of the other two (74.09 vs. 67.36 and 68.28 ), indicating a slightly more diffuse light reflection. In this case, the PSDs in Fig. 11a are not sufficient to explain the observations in colour measurements. We expect that the diffuse light reflection from "w1_dg_nb" could be enhanced by the light scattering through many fine horizontal lines on its gold surface, which we have observed in the DM image (Fig. 8b) and expect are the result of sanding marks on the chalk ground. Such fine horizontal lines can be also observed in the topography images of the "nb" and "b" sub-models of "w1_dg" (Fig. 11c, g), as well as the ground substrates of "w1_dg" and "w4_dg_oil" (Fig. 11j, k), but are not observable in the corresponding PSDs due to poor statistics at length scales above about $0.2 \mathrm{~mm}$. The vertical lines in "w4_dg_oil_nb" that have been observed in the DM image (Fig. 8c) can be also seen in its topography image (Fig. 11d); and the small wavy wrinkles present in the same image appear consistent with the drying process of the oil contained in the gold size.

The roughness comparison between "b1_dg_b" and "w1_dg_b" (Fig. 11e) seems rather clear, with "b1_dg_b" showing significantly lower roughness than "w1_dg_b" at length scales below $0.1 \mathrm{~mm}$. This lower roughness can be expected to result in a much less diffuse light reflection. Indeed, our colour measurements indicate that the $\mathrm{L}^{*}$ values of "b1_dg_b" and "w1_dg_b" are 36.76 and 53.10, respectively, which result in a significant colour difference by ca. 16 units ( $\Delta \mathrm{E}^{* * a b}$ value of 32.62 vs. 16.23). The comparison of these sub-models is a clear demonstration of how a soft substrate (i.e. bole) produces a superior burnished surface than hard substrates (i.e. polished ground).

\section{Conclusions}

Our analysis of colourimetry and surface roughness measurements on models made from modern gold leaves provides strong evidence that the substrate colour itself does not play an essential role in the colour appearance of the gold leaf laid above. Instead, we attribute the variations in visual perception to the surface roughness of the applied gold leaves, which can be affected by the properties of the substrate. Generally, for water gilding with bole substrates, the roughness of the substrate directly affects the gilded surface at length scales larger than $0.05 \mathrm{~mm}$ for the unburnished state, as the foil conforms to the largescale topography of the substrate. However, burnishing drastically changes the surface roughness and appearance of the gilding, which is affected by the substrate in a very different way. The effectiveness of the burnishing in achieving a high metal gloss is aided by the cushioning function provided by the substrate. For example, the bole substrate is soft and elastic and exhibits the best burnishing performance; while a hard chalk ground provides an inferior surface burnishing, leading to relatively higher diffuse light reflection from the gold surface. While the greatest colorimetric changes with burnishing were observed to be in the lightness axis $\left(\mathrm{L}^{*}\right)$, smaller but significant changes in the red-green axis $\left(\mathrm{a}^{*}\right)$ and yellow-blue axis $\left(b^{*}\right)$ were also observed that would help to explain the reported increase in warmth and depth of well burnished gold surfaces. The findings of this article build the foundation for further analysis of medieval gold leaf and its historical developments in Part II.

\section{Appendix}

Calculation formula of the colour difference with CIE L*a*b* coordinates [23]:

$$
\Delta E_{a b}^{*}=\sqrt{\left(L_{2}^{*}-L_{1}^{*}\right)^{2}+\left(a_{2}^{*}-a_{1}^{*}\right)^{2}+\left(b_{2}^{*}-b_{1}^{*}\right)^{2}}
$$

$\Delta \mathrm{L}^{*}\left(\mathrm{~L}^{*}\right.$ sample $-\mathrm{L}^{*}$ standard $)=$ difference in lightness and darkness ("+" refers lighter, "-" refers darker).

$\Delta \mathrm{a}^{*}\left(\mathrm{a}^{*}\right.$ sample $-\mathrm{a}^{*}$ standard $)=$ difference in red and green ("+" refers redder, "-"refers greener).

$\Delta \mathrm{b}^{*}$ (b* sample $-\mathrm{b}^{*}$ standard $)=$ difference in yellow and blue ("+" refers yellower, "-" refers bluer).

\section{Abbreviations}

b: Burnished; dg: Doppelgold; DM: Digital microscopy; JND: Just noticeable difference; MAV: Medium area view; nb: Unburnished; pg: Poliergold; PSD: Power specular density; PSI: Paul Scherrer Institute; SAV: Small area view; SCE: Specular component excluded; SCI: Specular component included; SEM-EDX: SCANNING electron microscopy coupled with energy dispersive X-ray analysis.

\section{Supplementary information}

Supplementary information accompanies this paper at https://doi.org/10. 1186/s40494-020-00463-3.

Additional file 1. Supporting evidence and further information.

\section{Acknowledgements}

The authors thank Peter Wyer, Vera Hubert, Erwin Hildbrand, Pascal Puphal, Ekaterina Pomjakushina and Rainer Fink for technical assistance. This work was supported by the Swiss National Museum Collection Centre (Switzerland), Paul Scherrer Institute (Switzerland) and University of Zurich (Switzerland).

\section{Authors' contributions}

QW designed the work, performed the colour measurements and digital microscopy imaging, analysed and interpreted all experimental data, and was a major contributor in writing the manuscript. $\mathrm{MH}$ produced the models. BR performed the interferometric microscopy experiments and analyzed the data. TL substantively revised the manuscript. KS substantively revised the manuscript. BW visualized the interferometric microscopy data and substantively revised the manuscript. FN substantively revised the manuscript. DG designed the work. All authors read and approved the final manuscript. 


\section{Funding}

Not applicable.

\section{Availability of data and materials}

The datasets used and/or analysed during this study are available from the corresponding author on reasonable request.

\section{Competing interests}

The authors declare that they have no competing interests.

\section{Author details}

${ }^{1}$ University of Zurich, Raemistrasse 73, 8006 Zurich, Switzerland. ${ }^{2}$ Bern University of the Arts, Fellerstrasse 11, 3027 Bern, Switzerland. ${ }^{3}$ Paul Scherrer Institute, Forschungsstrasse 111, 5232 Villigen PSI, Switzerland. ${ }^{4}$ Swiss National Museum-Collection Centre, Lindenmoosstrasse 1, 8910 Affoltern am Albis, Switzerland.

Received: 25 August 2020 Accepted: 1 November 2020 Published: 23 November 2020

\section{References}

1. Marinellie U. Polychrome Metamorphosen: Mittelalterliche Skulpturen in neuzeitlichen Fassungen. Innsbruck University Press; 2015.

2. Hradil D, Hradilová J, Bezdicka P, Serendan C. Late Gothic/early Renaissance gilding technology and the traditional poliment material 'Armenian bole': truly red clay, or rather bauxite? Appl Clay Sci. 2017;135:271-81. https://doi.org/10.1016/j.clay.2016.10.004.

3. Katsibiri $O$. Investigation of the technique and materials used for mordant gilding on Byzantine and post-Byzantine icons and wall paintings. Diploma thesis, University of Northumbria at Newcastle; 2002; cited by Hradil et al. 2017

4. Sandu ICA, de Sá MH, Pereira MC. Ancient 'gilded' art object from European cultural heritage: a review on different scales of characterization. Surf Interface Anal. 2011;43(8):1134-51. https://doi.org/10.1002/sia.3740.

5. Nadolny JM. The techniques and use of gilded relief decoration by northern European painters, C.1200-1500. Doctor thesis, Courtauld Institute of Art London; 2000

6. Cennini C. The Craftsman's Handbook: The Italian "Il libro dell'arte", translated by D, vol. Thompson. New York: Dover Publications Inc; 2012

7. Dumazet S, Gentry A, Zymla A, de Contencin F-X, Texier A, Ruscassier N, Bonnet B, Callet P. Influence of the substrate colour of the visual appearance of gilded sculptures. XXI International CIPA Symposium 2007.

8. Mounier A, Daniel F. The role of the under-layer in the coloured perception of gildings in medieval mural paintings. In: 38th International Symposium on Archaeometry, Tampa, Florida: Technology \& Provenance. Open Journal of Archaeometry 2013; 1: 1. https://doi.org/10.4081/arc. 2013.e16.

9. Straub, RE. "Tafel- und Tüchleinmalerei des Mittelalters". In: Reclams Handbuch der künstlerischen Techniken. Band 1. Stuttgart: Philipp Reclam jun.; 1984. p. 131-259

10. Mastrotheodoros GP, Beltsios KG, Bassiakos Y, Papadopoulou V. On the metal-leaf decorations of post-Byzantine Greek icons. Archaeometry. 2018;60(2):269-89. https://doi.org/10.1111/arcm.12287.

11. Perez-Rodriguez JL, Robador MD, Albardonedo A, Duran A. Gildings from Andalusia: materials used in different types of artworks along centuries. Journal of Cultural Heritage. 2018;31:112-21. https://doi.org/10.1016/j. culher.2017.11.009.

12. National Gallery. Methods and materials of Northern European painting in the National Gallery, 1400-1500. In: National Gallery Technical Bulletin. 1997; 18: 6-55. http://www.jstor.org/stable/42616111. Accessed 28 Feb 2018

13. Buchenrieder F. Gefasste Bildwerke: Untersuchung und Beschreibung von Skulpturenfassungen mit Beispielen aus der praktischen Arbeit der Restaurierungswerkstätten des Bayerischen Landesamtes für Denkmalpflege 1958-1986. München: Bayerisches Landesamt für Denkmalpfleg; 1990.

14. Berrie B. Rethinking the History of Artists' Pigments Through Chemical Analysis. Annu Rev Anal Chem. 2012;5:441-59. https://doi.org/10.1146/ annurev-anchem-062011-143039.
15. Fletcher A Glinsman L Oltrogge D. The Pigments on Hand-colored Fifteenth Century Relief Prints from the Collections of the National Gallery of Arts and Germanisches Museum. Studies in the History of Art 2009; 75: 276-97. https://www.jstor.org/stable/23923674. Accessed 28 Feb 2018.

16. Todd J, Norman JF. The visual perception of metal. J Vis. 2018;18:9. https:// doi.org/10.1167/18.3.9.

17. Konica Minolta: Colour and Gloss (SCE and SCI methods). https://www. konicaminolta.com/instruments/knowledge/color/part3/02.html. Accessed 29 Dec 2019.

18. Datacolor: Understanding Datacolor Gloss Compensation: a technical report on gloss and Datacolor's gloss compensation. https://knowledgeb ase.datacolor.com/admin/attachments/gloss_compensation_dci.pdf. Accessed 20 Dec 2019.

19. Callet P, Zymla A, Mofakhami A. Virtual metallurgy and archaeology application to the visual simulation of a work of art. In: I. team (ed.), Proceedings of ICCVG 2002, Zakopane: 25-29.

20. Loebich $O$. The optical properties of gold: a review of their technical utilization. Gold Bulletin. 1972:5:2-10. https://doi.org/10.1007/BF03215148.

21. Noris Blattgold: Dukaten Doppel Gold. https://noris-blattgold.de/blatt gold. Accessed 20 Dec 2019.

22. Hardeberg JY. Acquisition and reproduction of colour images: colorimetric and multispecular approaches. Dissertation.com. USA. 2001. http:// www.bookpump.com/dps/pdf-b/1121350b.pdf. Accessed 25 Dec 2019.

23. Konica Minolta: Identifying Color Differences Using $L^{*} a^{*} b^{*}$ or $L^{*} C^{*} H^{*}$ Coordinates. https://sensing.konicaminolta.us/us/blog/identifying-colordifferences-using-l-a-b-or-l-c-h-coordinates/. Accessed 20 Dec 2019.

24. Mahy M, van Eycken L, Oosterlinck A. Evaluation of uniform color spaces developed after the adoption of CIELAB and CIELUV. colour research and application 1994; cited by Hardeberg 2001.

25. Konica Minolta: Understanding Specular Component Included (SCI) and Specular Component Excluded (SCE). https://sensing.konicaminolta.asia/ specular-component-included-sci-vs-specular-component-excludedsce/. Accessed 29 Dec 2019.

26. Jacobs TDB, Junge T, Pastewka L. Quantitative characterization of surface topography using specular analysis. Surf. Topogr.: Metrol. Prop. 2017; 5: 1. https://doi.org/10.1088/2051-672x/aa51f8.

\section{Publisher's Note}

Springer Nature remains neutral with regard to jurisdictional claims in published maps and institutional affiliations.

\section{Submit your manuscript to a SpringerOpen ${ }^{\circ}$ journal and benefit from:}

- Convenient online submission

$\checkmark$ Rigorous peer review

- Open access: articles freely available online

- High visibility within the field

- Retaining the copyright to your article

Submit your next manuscript at springeropen.com 